\title{
Naphthalene metabolism and growth inhibition by naphthalene in Polaromonas naphthalenivorans strain CJ2
}

Correspondence

Eugene L. Madsen

elm3@cornell.edu

Received 18 June 2007

Revised 13 July 2007

Accepted 18 July 2007

\author{
Graham M. Pumphrey and Eugene L. Madsen \\ Department of Microbiology, Cornell University, Ithaca, NY 14853, USA
}

\section{INTRODUCTION}

Polycyclic aromatic hydrocarbons (PAHs) are widely distributed in the environment, and the toxic and carcinogenic characteristics of PAHs have motivated efforts to develop bioremediation technologies to eliminate sources of PAH exposure (Samanta et al., 2002; Xue \& Warshawsky, 2005). Naphthalene is commonly used as a model for studying PAH metabolism by bacteria because it is the simplest and most soluble $\mathrm{PAH}$, as well as a frequent constituent of PAH-contaminated environments (Peters et al., 1999). Studies of naphthalene degradation have shown that there are two primary pathways for the metabolism of naphthalene, which are distinguished by the conversion of salicylate to catechol or gentisate. Metabolism of naphthalene via catechol has been studied extensively in two Pseudomonas species that carry the archetypal catabolic plasmids NAH7 (in P. putida G7) and pDTG1 (in P. putida NCIB 9816-4) (Dennis \& Zylstra, 2004; Yen \& Serdar, 1988; Sota et al., 2006). The nah dissimilatory genes are organized into two operons: one

Abbreviations: DMF, N,N-dimethylformamide; $\mathrm{PAH}$, polycyclic aromatic hydrocarbon. encoding the enzymes involved in the conversion of naphthalene to salicylate (naphthalene degradation upper pathway) and another encoding the conversion of salicylate to catechol, followed by ortho- or meta-cleavage to TCA cycle intermediates (naphthalene degradation lower pathway) (Yen \& Gunsalus, 1982). In contrast, the nag genes found in Ralstonia sp. strain U2 are organized in a single operon and encode the alternative gentisate pathway, which converts naphthalene to fumarate and pyruvate via salicylate and gentisate (Fuenmayor et al., 1998; Zhou et al., 2002).

Although the genetics and biochemistry of naphthalene metabolism have been studied in depth, the inhibition of naphthalene metabolism due to the toxicity of naphthalene and naphthalene metabolites has received less attention (Auger et al., 1995; Murphy \& Stone, 1955; Park et al., 2004). Naphthalene has been reported to be directly toxic to $P$. putida G7 under oxygen- and nitrogen-limited conditions, although it is unclear if the toxicity was due to naphthalene or a naphthalene metabolite (Ahn et al., 1998). Naphthalene was also shown to be toxic to nonnaphthalene-degraders, as $P$. putida KT2440 showed reduced viability in soil amended with naphthalene (Park 
et al., 2004), and a bioluminescent strain of Escherichia coli showed reduced bioluminescence in the presence of naphthalene (Lee et al., 2003).

Polaromonas naphthalenivorans CJ2 was isolated from coaltar-contaminated freshwater sediment for its ability to use naphthalene as its sole carbon source, and was shown to be responsible for in situ naphthalene degradation by fieldbased stable isotope probing (Jeon et al., 2003). The naphthalene catabolic genes in strain CJ2 are homologous to the nag operon of Ralstonia sp. strain U2, but the genes are arranged in two separate clusters, each with its own regulatory protein (Jeon et al., 2006). In the present investigation, we show that strain CJ2 metabolizes naphthalene via the gentisate pathway using respirometry, GC-MS and cell-free enzyme assays. In addition, we explore the inhibitory effects of naphthalene and its metabolites on the growth of strain CJ2.

\section{METHODS}

Bacterial strains. $P$. naphthalenivorans strain CJ2 was isolated from freshwater sediment from a coal-tar-waste contaminated site (Jeon et al., 2003). Naphthalene degraders $P$. putida NCIB 9816-4 (Yen \& Serdar, 1988) and Ralstonia sp. strain U2 (Zhou et al., 2002) were included in this study for comparison. Strain CJN110 is a mutant of strain CJ2 in which the regulatory gene nagR has been disrupted by a suicide vector carrying a kanamycin resistance gene (Jeon et al., 2006).

Growth assays. All growth assays were conducted with Stanier mineral salts media (MSB; Stanier et al., 1966) supplemented with pyruvate $(18 \mathrm{mM})$, glucose $(6 \mathrm{mM})$ and/or naphthalene crystals. The aqueous concentration of naphthalene was lowered with Amberlite XAD7 resin. Naphthalene binds to the XAD7 resin, which acts as a reservoir, and maintains the aqueous concentration of naphthalene below saturation $(230 \mu \mathrm{M}$ or 30 p.p.m.) while supplying enough naphthalene to support growth over the course of the experiment (Morasch et al., 2001). Naphthalene (6-14 mg) was added to $6 \mathrm{ml} \mathrm{MSB}$ containing $0.1 \mathrm{~g} \mathrm{XAD7}$ before the tubes were sealed with Teflon-lined stoppers and autoclaved. To grow strain CJ2 in MSB saturated in naphthalene, a large inoculum $(>7 \%, v / v)$ from a dense starter culture was required. Viability of test bacteria was measured by enumerating c.f.u. from $10 \mu \mathrm{l}$ drops of serially diluted cultures on R2A agar. Kanamycin was added to media at $40 \mu \mathrm{g} \mathrm{ml}^{-1}$ when appropriate.

Respirometry. Bacterial cells were grown to late exponential phase in MSB with naphthalene $(0.5 \% \mathrm{w} / \mathrm{v})$ and harvested $(6000 \mathrm{~g})$. Cells were washed twice and resuspended in $50 \mathrm{mM} \mathrm{KH}_{2} \mathrm{PO}_{4}$ buffer ( $\mathrm{pH} 7.4$ ). Endogenous respiration was measured with an oxygen electrode (Rank Brothers) after adding $2 \mathrm{ml}$ washed cell suspension to the incubation chamber, and oxygen consumption was recorded following the addition of $20 \mathrm{mM}$ substrate dissolved in $\mathrm{N}, \mathrm{N}$ dimethylformamide (DMF). Respiration upon addition of DMF only was included as a control treatment.

Enzyme assays. Bacterial cells were grown in $500 \mathrm{ml}$ MSB with $18 \mathrm{mM}$ pyruvate or $4 \mathrm{mM}$ salicylate to late exponential phase, and cells were harvested by centrifugation $(6000 \mathrm{~g})$ and washed once with $50 \mathrm{mM} \mathrm{KH}_{2} \mathrm{PO}_{4}$ buffer ( $\mathrm{pH}$ 7.4). Cells were resuspended in buffer to a concentration of $0.1 \mathrm{~g} \mathrm{ml}^{-1}$ and sonicated three times for $30 \mathrm{~s}$ with $60 \mathrm{~s}$ cooling intervals. Cellular debris was cleared by centrifugation (25000 $\mathrm{g}$ for $45 \mathrm{~min}$ ) and protein concentrations were determined with the Bio-Rad Bradford assay. Enzyme assays were performed with a minimum of $50 \mu \mathrm{g}$ protein. The enzyme substrates, gentisate $(0.19 \mu \mathrm{mol})$ or catechol $(0.9 \mu \mathrm{mol})$, were added in $1 \mathrm{ml}$ volumes. Gentisate 1,2-dioxygenase activity was measured spectrophotometrically by measuring the increase of absorption at $334 \mathrm{~nm}$, due to the formation of maleylpyruvate, and was calculated with an extinction coefficient of $10800 \mathrm{M}^{-1} \mathrm{~cm}^{-1}$ (Crawford et al., 1975). Catechol 1,2dioxygenase activity was assayed by measuring the increase in absorption at $260 \mathrm{~nm}$, due to the formation of cis,cis-muconate, and was calculated with an extinction coefficient of $16800 \mathrm{M}^{-1} \mathrm{~cm}^{-1}$ (Dorn \& Knackmuss, 1978). Catechol 2,3-dioxygenase activity was measured by monitoring the increase in 2-hydroxy-cis,cis-muconate semialdehyde at $375 \mathrm{~nm}$, and was calculated with an extinction coefficient of $33000 \mathrm{M}^{-1} \mathrm{~cm}^{-1}$ (Cerdan et al., 1994).

GC-MS detection of naphthalene pathway metabolites. Cells $(500 \mathrm{ml})$ grown on naphthalene or pyruvate were harvested, washed

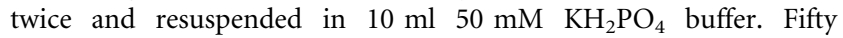
microlitres of $200 \mathrm{mM}$ naphthalene in DMF was added to $5 \mathrm{ml}$ of the concentrated cell suspension and metabolism was allowed to proceed for $15 \mathrm{~min}$. Suspensions were acidified with $\mathrm{HCl}$ to $\mathrm{pH} 1.5$ and extracted twice with $7.5 \mathrm{ml}$ ethyl acetate, which was then dried over anhydrous $\mathrm{Na}_{2} \mathrm{SO}_{4}$ and concentrated under an atmosphere of $\mathrm{N}_{2}$ to a volume of $300 \mu \mathrm{l}$. Extracts were derivatized with $25 \mu \mathrm{l}$ BSTFA [bis(trimethylsilyl)trifluoroacetimide] for $5 \mathrm{~min}$ prior to GC-MS analysis and quantified using external standard calibration curves.

HPLC analysis of naphthalene and inhibitory compounds. Naphthalene concentrations were determined by HPLC. Samples $(100 \mu \mathrm{l})$ were taken from culture tubes and immediately fixed in an equal volume of methanol. Samples were filtered through tightly packed glass wool prior to injection, and naphthalene was separated using a PAH-Hypersil column $(150 \times 4.6 \mathrm{~mm}$; Keystone Scientific $)$ and a Waters model 590 HPLC pump with a mobile phase of methanol/water $(65: 35)$ at a flow rate of $1 \mathrm{ml} \mathrm{min}^{-1}$. Eluents were monitored by UV-visible light detection (ABI analytical absorbance detector; Spectroflow 757) at a wavelength of $270 \mathrm{~nm}$ and quantified using an external standard calibration curve.

Putative naphthalene metabolites were separated with a Hypersil BDSC18 column $(4.6 \times 250 \mathrm{~mm}$; Agilent $)$ at a flow rate of $1 \mathrm{ml} \mathrm{min}^{-1}$ with a Spectra-Physics model SP8800 ternary HPLC pump. The mobile phase consisted of $20 \%$ methanol and $80 \% 40 \mathrm{mM}$ acetic acid for $10 \mathrm{~min}$, followed by a linear increase in methanol to $50 \%$ over $10 \mathrm{~min}$; after $5 \mathrm{~min}$ the methanol concentration was linearly increased to $90 \%$ over $10 \mathrm{~min}$ and held for $15 \mathrm{~min}$. Eluents were detected at $260 \mathrm{~nm}$ using a UV-Vis detector (SPD-10A VP; Shimadzu). Aged 1,2naphthoquinone solution $(50 \mu \mathrm{M}$ final concn) was prepared by diluting a filter-sterilized $10 \mathrm{mM}$ methanolic stock, aseptically adding it to sterile MSB and allowing the solution to shake for $48 \mathrm{~h}$.

\section{RESULTS}

\section{Respirometry}

To better understand the physiology of Polaromonas naphthalenivorans CJ2, we compared strain CJ2 with archetypal naphthalene-degrading bacteria Pseudomonas putida NCIB 9816-4 and Ralstonia sp. strain U2. The simultaneous induction of enzymes involved in naphthalene metabolism was compared in the three strains by measuring oxygen uptake after the introduction of potential naphthalene metabolites to washed cell suspensions (Fig. 1). The simultaneous adaptation assays were aimed at confirming that strain CJ2 metabolizes naphthalene via gentisate as 


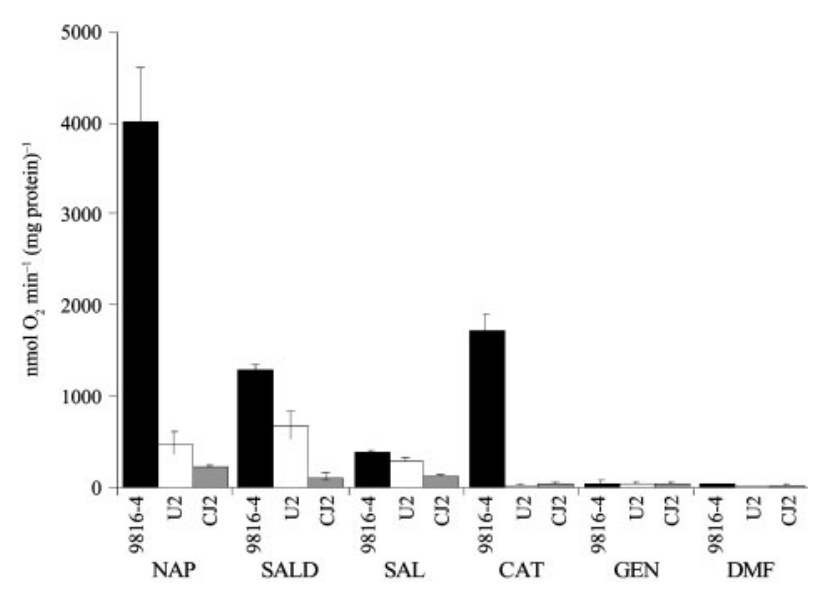

Fig. 1. Respiration by three strains of bacteria ( $P$. putida NCIB 9816-4, Ralstonia sp. strain U2 and $P$. naphthalenivorans strain CJ2) grown on naphthalene and exposed to naphthalene (NAP) and five potential metabolites [salicylaldehyde (SALD), salicylate (SAL), catechol (CAT), gentisate (GEN) and DMF]. The oxygen uptake experimental values represent the mean $I S D$ of triplicate experiments. All values are corrected for endogenous respiration of cells.

suggested by the sequence homology of the naphthalene catabolic operons in Ralstonia sp. strain U2 and strain CJ2, as well as to reveal potential physiological effects of the naphthalene catabolic gene arrangement in strain CJ2.

Consistent with the established metabolic pathway in $P$. putida NCIB 9816-4, these cells rapidly consumed oxygen after addition of naphthalene, salicylaldehyde, salicylate and catechol, while oxygen depletion was not rapid after the addition of gentisate (Fig. 1). Ralstonia sp. strain U2 cells consumed oxygen when exposed to naphthalene, salicylaldehyde and salicylate. Ralstonia sp. strain U2 cells, our positive control for the gentisate pathway, did not display enhanced respiration when exposed to gentisate (Fig. 1). Strain CJ2 consumed oxygen after addition of naphthalene, salicylaldehyde and salicylate. However, similar to Ralstonia sp. strain U2, neither gentisate nor catechol led to rapid depletion of oxygen. Ralstonia sp. strain $\mathrm{U} 2$ is known to lack a gentisate transporter ( $\mathrm{Xu}$ et al.,
2006), and if the same is true for strain CJ2, this accounts for the absence of enhanced oxygen uptake in the presence of gentisate. Regardless, the lack of enhanced oxygen uptake in the presence of catechol by Ralstonia sp. strain U2 and strain CJ2 reveals a key distinction between these two strains and P. putida NCIB 9816-4.

\section{Metabolite detection}

We measured potential naphthalene metabolites with GCMS to support the respirometry data and to eliminate ambiguity regarding the role of gentisate or catechol in the naphthalene metabolic pathway in strain CJ2. Again, $P$. putida NCIB 9816-4 and Ralstonia sp. strain U2 served as controls for the catechol and gentisate pathways, respectively. Table 1 shows the detected metabolites from washed cell suspensions that were incubated for $15 \mathrm{~min}$ after addition of naphthalene in DMF to a final concentration of $2 \mathrm{mM}$.

As expected for the nah pathway expressed by $P$. putida NCIB 9816-4, we detected cis-1,2-dihydroxydihydronaphthalene, 1,2-dihydroxynaphthalene, salicylaldehyde, salicylate and catechol. Likewise, as expected for the nag pathway expressed by Ralstonia sp. strain U2, we detected cis-1,2-dihydroxydihydronaphthalene, 1,2-dihydroxynaphthalene, salicylaldehyde, salicylate and gentisate. As suggested by the respirometry data, the metabolite profile for strain CJ2 is consistent with the genetic similarities between Ralstonia sp. strain U2 and strain CJ2. We detected cis-1,2-dihydroxydihydronaphthalene, 1,2-dihydroxynaphthalene, salicylaldehyde, salicylate and gentisate in strain CJ2 cell suspensions. The presence of gentisate and the absence of catechol provides clear evidence that strain CJ2 metabolizes naphthalene through the gentisate pathway.

\section{Dioxygenase assays}

To provide further evidence for naphthalene metabolism by the gentisate pathway in strain CJ2, dioxygenase assays were conducted with cell-free extract from induced (salicylate-grown) and non-induced (pyruvate-grown) strain CJ2, P. putida NCIB 9816-4 and Ralstonia sp. strain U2. Gentisate 1,2-dioxygenase activity was detected in

Table 1. Survey of metabolites produced by P. putida NCIB 9816-4, Ralstonia sp. strain U2 and strain CJ2

The experimental values represent the mean $\pm \mathrm{SD}$ of triplicate experiments. 1,2-DHDN, cis-1,2-Dihydroxydihydronaphthalene; 1,2-DHN, 1,2dihydroxynaphthalene; ND, not detected.

\begin{tabular}{|c|c|c|c|c|c|c|}
\hline \multirow[t]{2}{*}{ Bacteria } & \multicolumn{6}{|c|}{ Naphthalene metabolites detected $\left[\mu \mathrm{g}(\mathrm{mg} \text { protein })^{-1}\right]$} \\
\hline & 1,2-DHDN & 1,2-DHN & Salicylaldehyde & Salicylate & Catechol & Gentisate \\
\hline P. putida NCIB 9816-4 & $2870 \pm 1280$ & $1450 \pm 600$ & $2.3 \pm 2.2$ & $1520 \pm 86$ & $3.4 \pm 2.7$ & ND \\
\hline Ralstonia U2 & $1260 \pm 560$ & $1060 \pm 90$ & $4.0 \pm 3.3$ & $390 \pm 130$ & $\mathrm{ND}$ & $2.0 \pm 1.3$ \\
\hline Strain CJ2 & $2000 \pm 1320$ & $450 \pm 300$ & $3.6 \pm 1.4$ & $8.7 \pm 6.4$ & ND & $2.6 \pm 2.2$ \\
\hline
\end{tabular}


strain Ralstonia sp. strain U2 when the cultures were

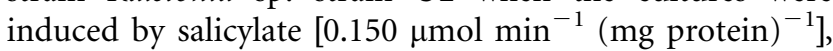
but not when grown on pyruvate $\left[0.004 \mu \mathrm{mol} \mathrm{min}^{-1}\right.$ (mg protein $)^{-1}$. Although gentisate dioxygenase activity was not as pronounced in strain CJ2, activity was induced by

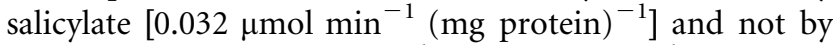
pyruvate $\left[0.003 \mu \mathrm{mol} \mathrm{min}{ }^{-1}(\mathrm{mg} \text { protein })^{-1}\right]$. Neither ortho- nor meta-cleavage of catechol was observed in strain CJ2 or Ralstonia sp. strain U2. As expected, P. putida NCIB 9816-4 displayed catechol 1,2-dioxygenase activity and no gentisate dioxygenase activity.

\section{Growth inhibition of strain CJ2 by naphthalene}

Although strain CJ2 was isolated under naphthalene vapour as a carbon source, a comparison of growth on naphthalene in minimal medium (MSB) between strain CJ2, P. putida NCIB 9816-4 and Ralstonia sp. strain U2 revealed unusual growth characteristics in strain CJ2. Both

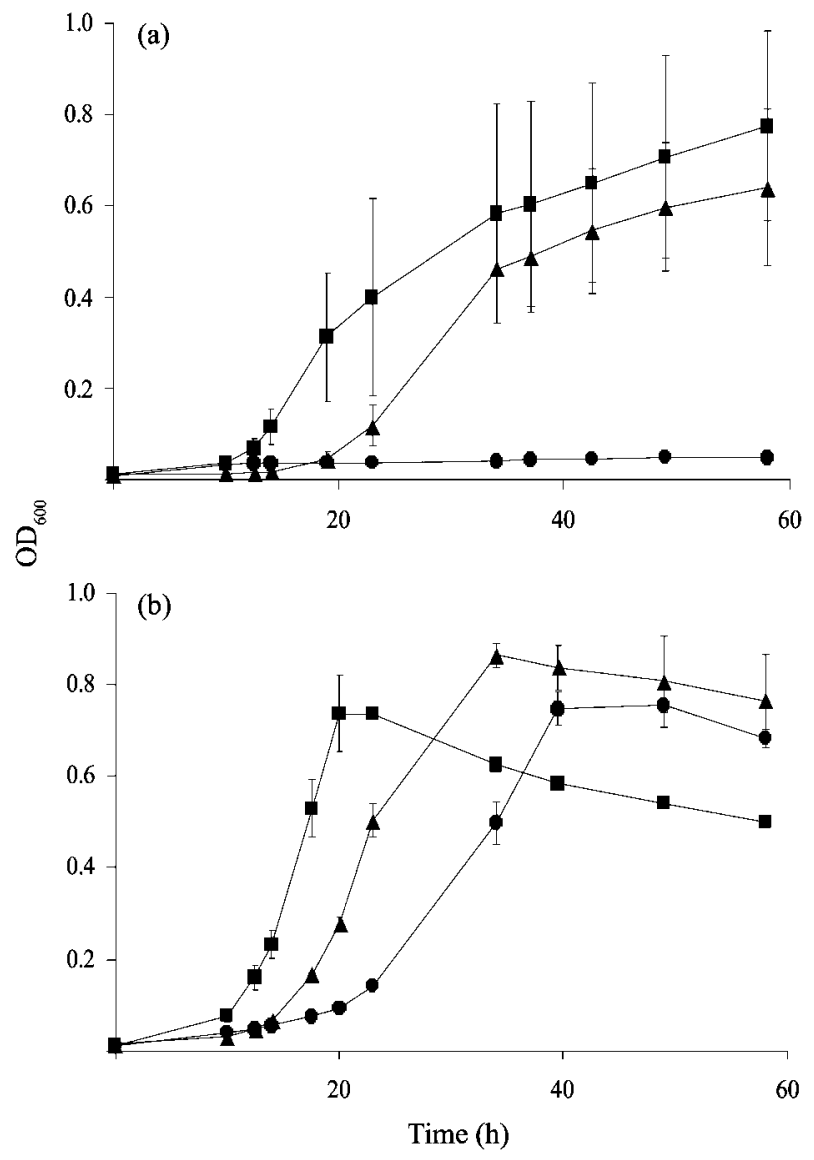

Fig. 2. Growth of naphthalene-degrading bacteria on mineral salts medium with naphthalene crystals (a) or pyruvate (b). Unlike $P$. putida NCIB 9816-4 (ם) and Ralstonia sp. strain U2 ( $\mathbf{\Delta})$, which grew equally well with pyruvate and naphthalene, strain CJ2 (•) grew only in MSB with pyruvate but not in MSB saturated with naphthalene. The experimental values represent the mean $\pm S D$ of triplicate experiments.
P. putida NCIB 9816-4 and Ralstonia sp. strain U2 grew equally well in MSB broth supplemented with $18 \mathrm{mM}$ pyruvate or saturated with naphthalene crystals $(\sim 230 \mu \mathrm{M})$. In contrast, strain CJ2 was unable to grow in MSB broth supplemented with naphthalene crystals (Fig. 2a), but grew well in MSB broth with $18 \mathrm{mM}$ pyruvate (Fig. 2b), demonstrating that the inhibition of growth is substrate-specific. Additionally, the lack of growth in MSB supplemented with naphthalene was accompanied by the appearance of a light orange colour in the medium, indicating the possible accumulation of naphthalene metabolites. Incidentally, growth of strain CJ2 in MSB saturated with naphthalene was influenced by cell density, as growth occurred if a large inoculum $(>7 \%)$ of a dense starter culture was used (data not shown).

\section{Naphthalene concentration and growth inhibition}

To test the effect of naphthalene concentration on growth inhibition, we grew strain CJ2 in MSB broth with $0.1 \mathrm{~g}$ XAD7 resin that had been equilibrated with different masses of naphthalene. This procedure has been shown to buffer the aqueous naphthalene concentration at levels proportional to the added mass (Morasch et al. 2001). Once an equilibrium was established between XAD7bound naphthalene and aqueous naphthalene, strain CJ2 was inoculated (initial cell density $1.56 \times 10^{6}$ c.f.u. $\mathrm{ml}^{-1}$ ) into media with initial aqueous concentrations of naphthalene of approximately $23,40,55,78$ or $100 \mu \mathrm{M}$, as determined by HPLC analysis of aqueous naphthalene in sterile medium. Growth was strongly inhibited when the initial naphthalene concentration in the medium was higher than $78 \mu \mathrm{M}$. However, strain CJ2 grew well when the initial naphthalene concentration of the medium was at

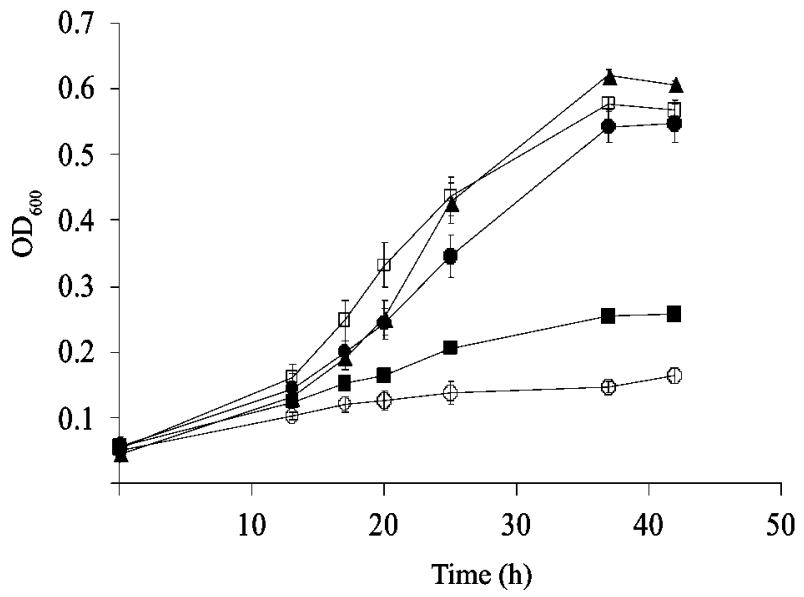

Fig. 3. Growth of strain CJ2 in MSB medium with initial aqueous naphthalene concentrations $(23-100 \mu \mathrm{M})$ buffered by XAD7 resin. Growth was inhibited at concentrations of $78 \mu \mathrm{M}$ and higher. The experimental values represent the mean $\pm \mathrm{SD}$ of triplicate experiments. $\square, 23 \mu \mathrm{M} ; \boldsymbol{\Delta}, 40 \mu \mathrm{M} ; \bullet, 55 \mu \mathrm{M} ; \boldsymbol{\square}, 78 \mu \mathrm{M}$;, $100 \mu \mathrm{M}$ naphthalene. 
or below $55 \mu \mathrm{M}$ (Fig. 3). This indicates that growth inhibition by naphthalene is concentration-dependent, with optimum growth occurring at $\sim 40 \mu \mathrm{M}$ naphthalene and inhibitory effects manifest above $\sim 78 \mu \mathrm{M}$ naphthalene.

\section{Direct inhibition by naphthalene}

The hypotheses for explaining the inhibitory effect of naphthalene on strain CJ2 are: (i) naphthalene itself could be directly inhibitory or toxic when present at high concentrations; (ii) the metabolism of naphthalene could lead to the accumulation of toxic or inhibitory metabolites when a high concentration of naphthalene is available to the cells; or (iii) both naphthalene and its metabolites play a role in growth inhibition.

To determine if naphthalene is directly toxic to strain CJ2, we measured the growth of CJN110, a NagR1 regulatory mutant of CJ2 that is unable to grow on naphthalene (Jeon et al., 2006), in MSB supplemented with $6 \mathrm{mM}$ glucose in the presence of naphthalene at concentrations that were inhibitory or non-inhibitory to the wild-type strain. Partially inhibited growth occurred on glucose in the presence of $23 \mu \mathrm{M}$ naphthalene. However, at all other naphthalene concentrations, growth on glucose was severely inhibited (Fig. 4). Because strain CJN110 is unable to metabolize naphthalene, inhibition of growth was not due to the production of potentially toxic naphthalene metabolites. Therefore, naphthalene has a direct inhibitory or toxic effect on strain CJN110 derived from strain CJ2.

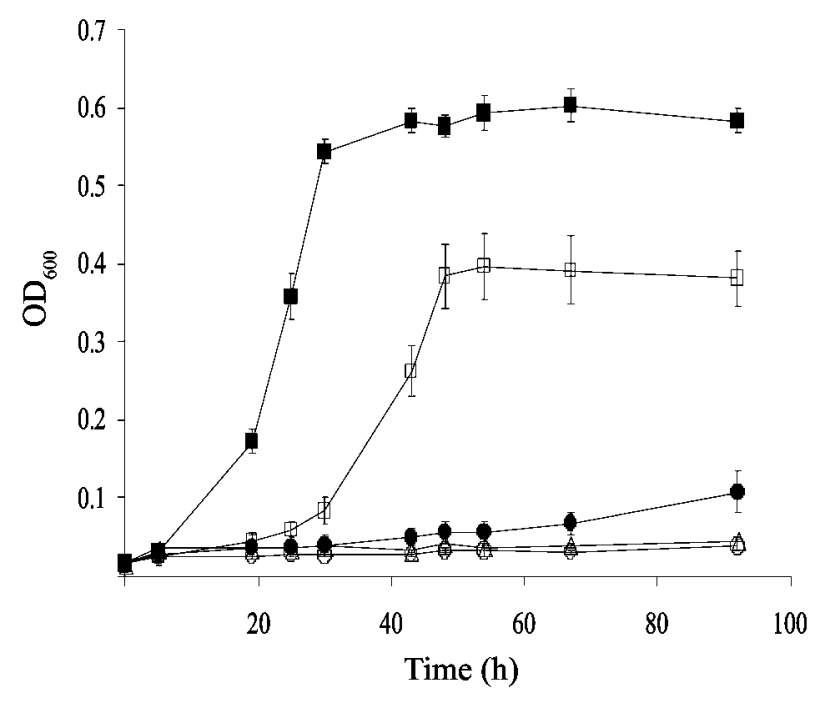

Fig. 4. Growth of a regulatory mutant of strain CJ2 (strain CJN110, NagR ${ }^{-}$) in glucose with or without naphthalene. The experimental values represent the mean \pm SD of triplicate experi-

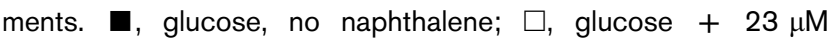
naphthalene; $\bullet$, glucose $+40 \mu \mathrm{M}$ naphthalene; $\bigcirc$, glucose + $55 \mu \mathrm{M}$ naphthalene; $\triangle, 23 \mu \mathrm{M}$ naphthalene, no glucose.

\section{Evidence for the production of toxic metabolites}

To explore the relationship between naphthalene concentration and growth inhibition, cell viability and naphthalene concentration were monitored over the course of a growth experiment. Strain CJ2 was inoculated into tubes containing MSB with $6 \mathrm{mM}$ glucose or $0.1 \mathrm{~g}$ naphthalene-loaded XAD7 resin, resulting in initial aqueous naphthalene concentrations of 31,47 and $86 \mu \mathrm{M}$, respectively.

Growth occurred as expected in cultures containing 6 or $10 \mathrm{mg}$ naphthalene (Fig. 5a), with both culture conditions reaching an $\mathrm{OD}_{600}$ near 0.68 and cultures containing $10 \mathrm{mg}$ growing slightly slower than those containing $6 \mathrm{mg}$. However, in tubes containing $12 \mathrm{mg}$ naphthalene, growth was severely inhibited and did not exceed an $\mathrm{OD}_{600}$ of 0.13 . The aqueous naphthalene concentration dropped below $10 \mu \mathrm{M}$ in cultures with $6 \mathrm{mg}$ naphthalene (Fig. 5b), suggesting that strain CJ2 metabolized naphthalene faster than it was diffusing from the XAD7 resin. In cultures containing 10 or $12 \mathrm{mg}$ naphthalene there was an initial increase in the aqueous naphthalene concentration, indicating that a new equilibrium was established upon the addition of the cells. The subsequent decrease in naphthalene concentration shows that even the inhibited cultures were metabolizing naphthalene.

Though growth was inhibited in cultures containing $12 \mathrm{mg}$ naphthalene, viable cells were detected until 34 h (Fig. 5c). However, after $34 \mathrm{~h}$ no viable cells were detected, and the loss of viability corresponded with the appearance of a light orange colour in the media, which appeared between 34 and $47 \mathrm{~h}$. These results suggest that not only does naphthalene have an inhibitory effect, but also naphthalene metabolism by inhibited cells results in the accumulation of a naphthalene metabolite that is toxic to the cells. It should be noted that even though there was no visible colour accumulation prior to $34 \mathrm{~h}$, it is possible that a low level of the toxic metabolite had accumulated and was responsible for growth inhibition.

\section{Analysis of toxic accumulated metabolites}

Previous reports have suggested that the accumulation of an orange metabolite in naphthalene-metabolizing cultures results from the abiotic oxidative transformation of 1,2dihydroxynaphthalene to 1,2-naphthoquinone (Auger et al., 1995; Davies \& Evans, 1964; Murphy \& Stone, 1955). Spectrophotometric scans $(240-400 \mathrm{~nm})$ of 1,2-naphthoquinone standards and coloured media from naphthaleneinhibited cultures of strain CJ2 suggested that 1,2naphthoquinone was present at concentrations between 50 and $100 \mu \mathrm{M}$ (data not shown). Therefore, we used HPLC to compare 1,2-naphthoquinone standards (dissolved in MSB) with media from strain CJ2 cultures that were either successfully grown on naphthalene or cultures that were inhibited by naphthalene and had accumulated orange-coloured metabolites. 

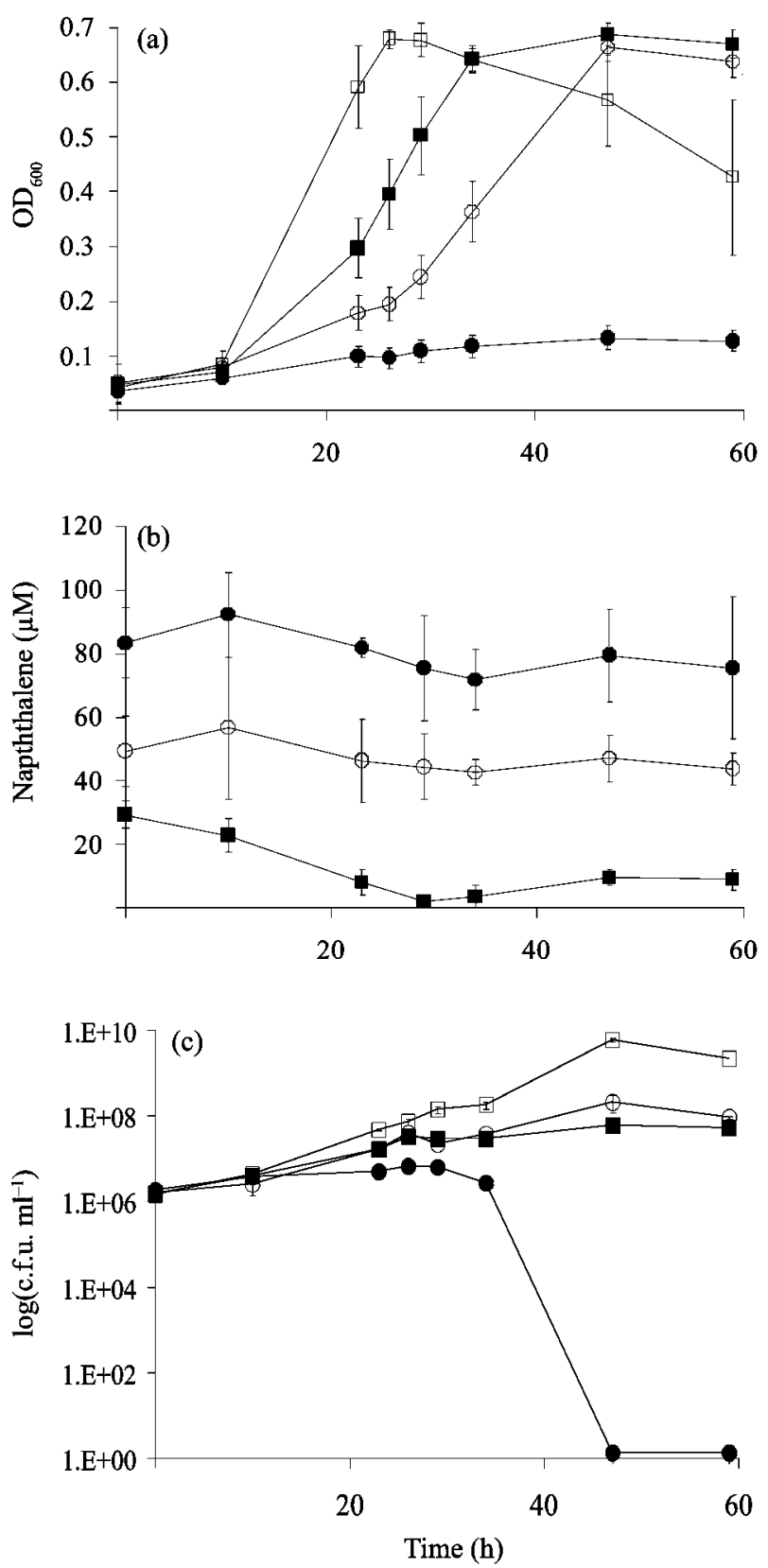

Fig. 5. Relationship between cell growth, aqueous naphthalene concentration and cell viability. Strain CJ2 was inoculated into MSB with glucose $(\square)$ or $0.1 \mathrm{~g} \mathrm{XAD7}$ and $6(\boldsymbol{\square}), 10(\bigcirc)$ or 12 (๑) $\mathrm{mg}$ naphthalene. Optical density (a), aqueous naphthalene concentration (b) and viable cells (c) were monitored. Inoculum density was held constant at $9.8 \times 10^{6}$ c.f.u.

Analysis of 1,2-naphthoquinone dissolved in MSB revealed that it too was unstable in aqueous media. When $50 \mu \mathrm{M}$ 1,2-naphthoquinone was analysed by HPLC shortly after dissolution in MSB, there was one major peak with a retention time of $20 \mathrm{~min}$ (peak II in Fig. 6a). A probable oxidation product with a retention time of 24 min (peak III in Fig. 6a) also appeared. However, after $50 \mu \mathrm{M}$ 1,2-naphthoquinone was incubated for $48 \mathrm{~h}$ in sterile MSB, peak II was no longer detected, while new peaks (I and IV) with retention times of 15 and $26 \mathrm{~min}$, respectively, were abiotically produced (Fig. 6b). Analysis of the coloured medium from a naphthalene-inhibited culture showed three peaks: one peak (II) corresponds with the primary peak of freshly dissolved 1,2-naphthoquinone, while the other two peaks, I and IV, correspond with daughter products of aged 1,2-naphthoquinone (Fig. 6c). No peaks of putative inhibitory metabolites were present in the uncoloured medium from cultures of CJ2 that successfully grew on naphthalene (Fig. 6d). Chemical instability, ineffective derivatization procedures and lack of authentic standards prevented GC-MS identification of the putative toxic compounds eluting as peaks I and IV in the inhibited culture of strain CJ2 (Fig. 6c). Support for the contribution of 1,2-naphthoquinone (peak II) to toxicity was obtained in assays showing that growth of strain CJ2 was completely inhibited in MSB-glucose medium when 1,2-naphthoquinone was present at a concentration of $\sim 50 \mu \mathrm{M}$ (data not shown).

\section{DISCUSSION}

The isolation of strain $\mathrm{CJ} 2$ has provided a unique opportunity to investigate the genetics and physiology of a bacterium that is linked to the in situ biodegradation of naphthalene in contaminated sediment. Sequencing of the naphthalene catabolic genes has revealed a novel arrangement of structural and regulatory genes in strain CJ2 (Jeon et al., 2006). In this study, we gained insight into the physiology of naphthalene metabolism in strain CJ2 by comparing it to two archetypal naphthalene-degrading bacteria. Our data from respirometry, metabolite detection by GC-MS and enzyme assays showed that strain CJ2 metabolizes naphthalene via the gentisate pathway. Growth assays revealed that strain CJ2 cannot grow on naphthalene at concentrations above $78 \mu \mathrm{M}$, and that metabolic imbalances may lead to inhibition and toxicity.

Bacteria that metabolize aromatic hydrocarbons face the challenge of acquiring carbon and energy from compounds that are potentially toxic (Ramos et al., 2002; Sikkema et al., 1995). The inability of potential biodegrading populations to tolerate aromatic hydrocarbon toxicity may contribute to the persistence of pollutants in the environment. The mechanisms of toxicity are generally believed to be disruption of biological membranes (Sikkema et al., 1995) and the production of toxic metabolites (e.g. Park et al., 2004). The lipophilic character of aromatic hydrocarbons can alter membrane fluidity, permeablize the membrane and cause swelling of the lipid bilayer. Alteration of membrane structure can disrupt energy transduction and the activity of membrane-associated proteins (Sikkema et al., 1995). Additionally, metabolites of aromatic compounds, such as catechols and quinones, can be more toxic than the parent compound due to an increase in solubility, production of reactive oxygen 


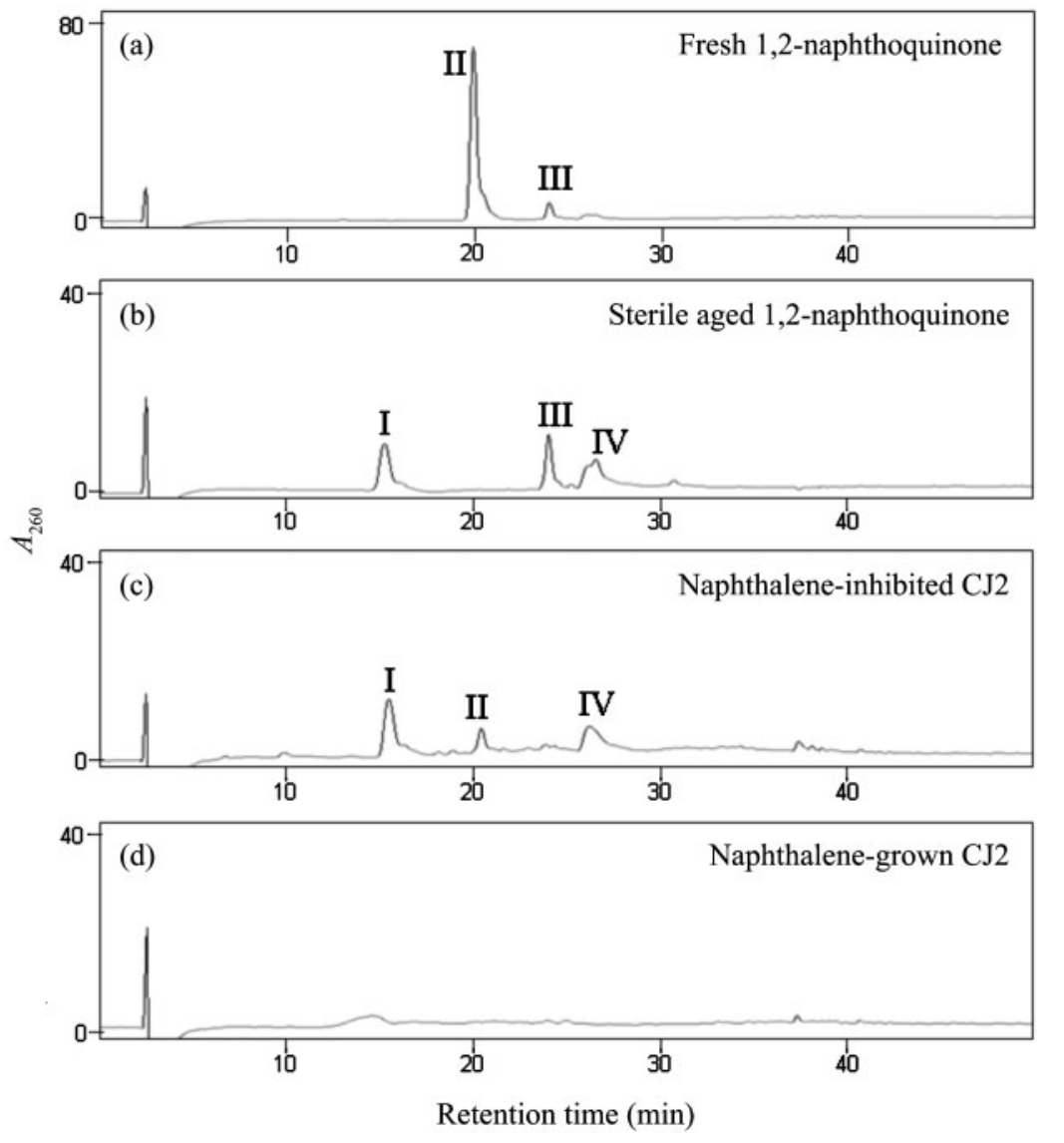

Fig. 6. Metabolite analysis by HPLC. Chromatograms of $50 \mu \mathrm{M} \quad 1,2$-naphthoquinone freshly dissolved in MSB medium (a), $50 \mu \mathrm{M}$ 1,2-naphthoquinone aged in sterile MSB medium for $48 \mathrm{~h}(\mathrm{~b})$, culture medium from naphthalene-inhibited strain CJ2 (c) and culture medium from naphthalene-grown strain CJ2 (d). Note that the vertical scale in (a) is twice that of the other panels. species, or adduct formation with DNA and proteins (Penning et al., 1999; Schweigert et al., 2001).

In the present investigation we have shown that Polaromonas naphthalenivorans CJ2 is susceptible to both (i) direct naphthalene inhibition and (ii) formation of toxic intermediate metabolites. Naphthalene inhibited the growth of strain CJ2 at concentrations of $55 \mu \mathrm{M}$ (Fig. 4), which is well below the aqueous saturation point of naphthalene $(230 \mu \mathrm{M})$. Naphthalene has been reported to be toxic to the archetypal naphthalene degraders $P$. putida G7 and P. putida NCIB 9816-4, but only under nitrogenor oxygen-limiting conditions (Ahn et al., 1998) or during incubation in soil amended with a high concentration $(0.2 \% \mathrm{w} / \mathrm{v})$ of naphthalene crystals (Park et al., 2004), respectively. We found that inhibition of strain CJ2 by naphthalene was independent of metabolism, and, based on the study of Sikkema et al. (1994), we speculate that the mechanisms of direct inhibition are likely to be related to impaired membrane function.

In addition to growth inhibition, naphthalene metabolism by strain CJ2 at inhibitory concentrations resulted in the accumulation of toxic oxidation products derived from 1,2-naphthoquinone, which resulted in a complete loss of viability (Figs 5c and 6c). Davies \& Evans (1964) showed that a $25 \mu \mathrm{M}$ solution of 1,2-dihydroxynaphthalene is converted by non-enzymic oxidation to 1,2-naphthoquinone at a rate of approximately $20 \% \mathrm{~min}^{-1}$ at $\mathrm{pH}$ 6.5. 1,2Naphthoquinone has been reported to accumulate and inhibit both growth and naphthalene metabolism when ferrous and magnesium salts are omitted from growth media (Murphy \& Stone, 1955) or when naphthalene bioavailability is increased by the addition of surfactant (Auger et al., 1995). Our analysis by HPLC suggests that 1,2-naphthoquinone (presumably produced abiotically from 1,2-dihydroxynaphthalene) and two abiotic transformation products of 1,2-naphthoquinone accumulate when strain CJ2 is exposed to inhibitory concentrations of naphthalene.

Strain CJ2 was shown to metabolize naphthalene in situ by stable isotope probing, which suggests that strain CJ2 is an active member of the naphthalene-degrading population in the sediment (Jeon et al., 2003). Strain CJ2 has evolved, apparently successfully, to occupy a niche as a naphthalene degrader, even though naphthalene has a strong inhibitory effect and subsaturation levels of naphthalene can result in toxic metabolite accumulation. It is possible that strain CJ2 never experienced selective pressure to develop greater tolerance to naphthalene because adsorption to soil and metabolism of naphthalene by other bacteria kept naphthalene concentrations well below inhibitory levels. If this is the case, strain CJ2 may not have evolved 
adaptation mechanisms frequently associated with tolerance to aromatic compounds, such as membrane isomerization and efflux pumps (Ramos et al., 2002). Furthermore, the accumulation of 1,2-naphthoquinonerelated oxidation products might be due to unrealistic naphthalene concentrations imposed in laboratory incubations combined with the slow growth of strain CJ2. An enzyme in the naphthalene catabolic pathway may have a low specific activity that is only problematic when the concentration of naphthalene exceeds a threshold. Another possibility is that if strain CJ2 is adapted to low naphthalene bioavailability in soil, the bacterium has evolved to accumulate as much naphthalene as possible, whether through active uptake or through modifications of the cell membrane and envelope. Thus, when presented with naphthalene at the concentrations used in this study, strain CJ2 accumulated naphthalene to inhibitory and toxic quantities.

This study also showed that strain CJ2 metabolizes naphthalene via gentisate using the nag-type pathway found in Ralstonia sp. strain U2. Metabolism of aromatics via gentisate has been studied less extensively than metabolism via catechol, and it is not clear whether one pathway has an advantage over the other. A study investigating bacteria that metabolize 3-chlorobenzoate suggested that micro-organisms using the gentisate pathway have lower maximum specific growth rates and lower apparent half-saturation constants for oxygen and 3chlorobenzoate; thus, they may be well adapted to substrate- and/or oxygen-limited conditions (Krooneman et al., 2000). If these same characteristics are applicable to strain CJ2, they could help explain why it is successful in naphthalene-contaminated sediments despite being sensitive to inhibitory effects of naphthalene.

\section{ACKNOWLEDGEMENTS}

This research was supported by NIEHS training grants 5-T32ES00752-28 and R21 ES012834.

\section{REFERENCES}

Ahn, I. S., Ghiorse, W. C., Lion, L. W. \& Shuler, M. L. (1998). Growth kinetics of Pseudomonas putida G7 on naphthalene and occurrence of naphthalene toxicity during nutrient deprivation. Biotechnol Bioeng 59, 587-594.

Auger, R. L., Jacobson, A. M. \& Domach, M. M. (1995). Effect of nonionic surfactant addition on bacterial metabolism of naphthalene: assessment of toxicity and overflow metabolism potential. $J$ Hazard Mater 43, 263-272.

Cerdan, P., Wasserfallen, A., Rekik, M., Timmis, K. N. \& Harayama, S. (1994). Substrate specificity of catechol 2,3-dioxygenase encoded by TOL plasmid pWWO of Pseudomonas putida and its relationship to cell growth. J Bacteriol 176, 6074-6081.

Crawford, R. L., Hutton, S. W. \& Chapman, P. J. (1975). Purification and properties of gentisate 1,2-dioxygenase from Moraxella osloensis. J Bacteriol 121, 794-799.
Davies, J. I. \& Evans, W. C. (1964). Oxidative metabolism of naphthalene by soil pseudomonads. The ring-fission mechanism. Biochem J 91, 251-261.

Dennis, J. J. \& Zylstra, G. J. (2004). Complete sequence and genetic organization of pDTG1, the 83-kilobase naphthalene degradation plasmid from Pseudomonas putida NCIB 9816-4. J Mol Biol 341, 753-768.

Dorn, E. \& Knackmuss, H.-J. (1978). Chemical structure and biodegradability of halogenated aromatic compounds. Biochem $\mathrm{J}$ 174, 85-94.

Fuenmayor, S. L., Wild, M., Boyes, A. L. \& Williams, P. A. (1998). A gene cluster encoding steps in conversion of naphthalene to gentisate in Pseudomonas sp. Strain U2. J Bacteriol 180, 2522-2530.

Jeon, C. O., Park, W., Padmanabhan, P., DeRito, C., Snape, J. R. \& Madsen, E. L. (2003). Discovery of a bacterium, with distinctive dioxygenase, that is responsible for in situ biodegradation in contaminated sediment. Proc Natl Acad Sci U S A 100, 13591-13596.

Jeon, C. O., Park, M., Ro, H. S., Park, W. \& Madsen, E. L. (2006). The naphthalene catabolic (nag) genes of Polaromonas naphthalenivorans CJ2: evolutionary implications for two gene clusters and novel regulatory control. Appl Environ Microbiol 72, 1086-1095.

Krooneman, J., Sliekers, A. O., Pedro Gomes, T. M., Forney, L. J. \& Gottshal, J. C. (2000). Characterization of 3-chlorobenzoate degrading aerobic bacteria isolated under various environmental conditions. FEMS Microbiol Ecol 32, 53-59.

Lee, H. J., Villaume, J., Cullen, D. C., Kim, B. C. \& Gu, M. B. (2003). Monitoring and classification of PAH toxicity using an immobilized bioluminescent bacteria. Biosens Bioelectron 18, 571-577.

Morasch, B., Annweiler, E., Warthmann, R. J. \& Meckenstock, R. U. (2001). The use of a solid adsorber resin for enrichment of bacteria with toxic substrates and to identify metabolites: degradation of naphthalene, $o$-, and $m$-xylene by sulfate-reducing bacteria. J Microbiol Methods 44, 183-191.

Murphy, J. F. \& Stone, R. W. (1955). The bacterial dissimilation of naphthalene. Can J Microbiol 1, 579-588.

Park, W., Jeon, C. O., Cadillo, H., DeRito, C. \& Madsen, E. L. (2004). Survival of naphthalene-degrading Pseudomonas putida NCIB 9816-4 in naphthalene-amended soils: toxicity of naphthalene and its metabolites. Appl Microbiol Biotechnol 64, 429-435.

Penning, T. M., Burczynski, M. E., Hung, C. F., McCoull, K. D., Palackal, N. T. \& Tsuruda, L. S. (1999). Dihydrodiol dehydrogenases and polycyclic aromatic hydrocarbon activation: generation of reactive and redox active o-quinones. Chem Res Toxicol 12, 1-18.

Peters, C. A., Knightes, C. D. \& Brown, D. G. (1999). Long-term composition dynamics of PAH-containing NAPLs and implications for risk assessment. Environ Sci Technol 33, 4499-4507.

Ramos, J. L., Duque, E., Gallegos, M. T., Godoy, P., RamosGonzalez, M. I., Rojas, A., Teran, W. \& Segura, A. (2002). Mechanisms of solvent tolerance in Gram-negative bacteria. Annu Rev Microbiol 56, 743-768.

Samanta, S. K., Singh, O. V. \& Jain, R. K. (2002). Polycyclic aromatic hydrocarbons: environmental pollution and bioremediation. Trends Biotechnol 20, 243-248.

Schweigert, N., Zehnder, A. J. \& Eggen, R. I. (2001). Chemical properties of catechols and their molecular modes of toxic action in cells, from microorganisms to mammals. Environ Microbiol 3, 81-91.

Sikkema, J., de Bont, J. A. \& Poolman, B. (1994). Interactions of cyclic hydrocarbons with biological membranes. J Biol Chem 269, 8022-8028. 
Sikkema, J., de Bont, J. A. \& Poolman, B. (1995). Mechanisms of membrane toxicity of hydrocarbons. Microbiol Rev 59, 201-222.

Sota, M., Yano, H., Ono, A., Miyazaki, R., Ishii, H., Genka, H., Top, E. M. \& Tsuda, M. (2006). Genomic and functional analysis of the IncP-9 naphthalene-catabolic plasmid NAH7 and its transposon Tn4655 suggests catabolic gene spread by a tyrosine recombinase. J Bacteriol 188, 4057-4067.

Stanier, R. Y., Palleroni, N. J. \& Doudoroff, M. (1966). The aerobic pseudomonads: a taxonomic study. J Gen Microbiol 43, 159-271.

Xu, Y., Yan, D. Z. \& Zhou, N. Y. (2006). Heterologous expression and localization of gentisate transporter Ncg12922 from Corynebacterium glutamicum ATCC 13032. Biochem Biophys Res Commun 346, 555-561.
Xue, W. \& Warshawsky, D. (2005). Metabolic activation of polycyclic and heterocyclic aromatic hydrocarbons and DNA damage: a review. Toxicol Appl Pharmacol 206, 73-93.

Yen, K. M. \& Gunsalus, I. C. (1982). Plasmid gene organization: naphthalene/salicylate oxidation. Proc Natl Acad Sci U S A 79, 874-878.

Yen, K. M. \& Serdar, C. M. (1988). Genetics of naphthalene catabolism in pseudomonads. Crit Rev Microbiol 15, 247-268.

Zhou, N. Y., Al-Dulayymi, J., Baird, M. S. \& Williams, P. A. (2002). Salicylate 5-hydroxylase from Ralstonia sp. strain U2: a monooxygenase with close relationships to and shared electron transport proteins with naphthalene dioxygenase. J Bacteriol 184, 1547-1555.

Edited by: H. L. Drake 